\title{
The effect of light and colour in architectural design
}

\author{
M. Mahan ${ }^{1} \&$ S. Kashizadeh ${ }^{2}$ \\ ${ }^{I}$ Department of Architecture, Islamic Azad University Heris Branch, Iran \\ ${ }^{2}$ Department of Architecture, Sama Technical and Vocational Training \\ College, Islamic Azad University Sahand Branch, Iran
}

\begin{abstract}
The purpose of this research is to identify the effect of light and colour on the quality of space perception. The presence of light is related to the age when humans knew themselves and grew and developed in the embrace of beautiful nature. It has a great place in science, variant religions, mysticism and Sufism, literature, philosophy, and numerous philosophies and scientists have studied it. In most religions it is a symbol of divine wisdom, the source of all wellness and innocence, and indeed it is a sign of the heavens and spiritual world. The main aim of life is the departure of humans from the darkness of foolishness and their entrance into the brilliant light of divine sapience and sight. The beauty which we see and understand is because of the presence of light, otherwise there is nothing in darkness. The real beauty is understood by the light of wisdom. It is the brilliance and shiny light that causes beauty, colours and other observable properties to be seen. Light is one of the important factors in architecture that is regarded along with other aspects such as structure, spatial order, materials, colour and so on. It also has a separate role in design. Colour is one of light's properties. Recognition of colour results from radiated light and its changes, the attraction, reflection and transmission properties of the surface, the relation of the surface with colours around it, and the characteristics of the eye. Colour plays a significant role in stimulating the observer. Additionally, it is important in the presentation and concealment of elements and their effects. In the present research we point to the effect of light and colour and their features in space perception in a case study we have undertaken in Iran.

Keywords: architectural design, colour, light, quality of space perception.
\end{abstract}




\section{Introduction}

Man's structural and spiritual health is dependent upon light. The aim of this paper is to emphasize the relation of preserving man's mental and moral balance, physical health, growth, prosperity, creativity and quality of life due to his responsiveness to the environment and light. In the world's literature, stories, explanations and metaphoric interpretations it has always been the case that warmth has been accompanied by brightness and light, and cold accompanied by darkness. This subject solely addresses visible light and does not deal with other topics such as invisible light like ultraviolet radiation, etc., which the human eye is not able to perceive [1].

It is clear that the existence and survival of humanity and also learning and continuous improvement and the promotion of the quality of life of most people are dependent on looking and seeing and surely light is required for seeing. Certainly if there were no light, life would not exist [2]. It was the photophilic phenomena that gave life success to man. By considering the extensive range of light usage in everyday life, industry, medicine, etc, the aim of the present paper in connection with this issue is helping to identify the quality effect of light on physical balance (physiological and ethical) by considering the effect of the environment on the growth and improvement of humans which ultimately leads to improving the quality of their lives.

\section{Light}

Light creates whiteness and brightness and accompanies everything that is relaxation and good. Always in movies and stories the good appear with white and bright clothes and put on white hats in which the eyes have a most important role in transferring this feeling through the light and seeing. Humans transfer most of their information to the brain through the eyes. Among the five human

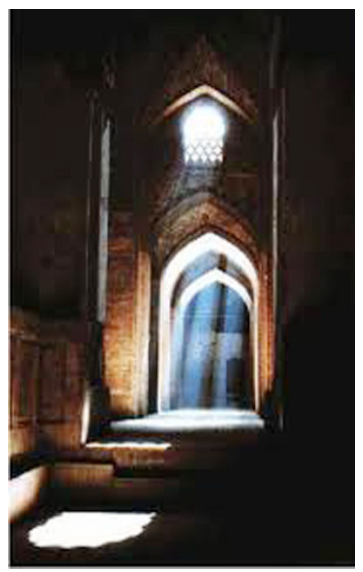

Figure 1: Example of light effect on the quality of space perception. 
senses, vision is the most important sense of transition. However, there are some other effective factors and elements in aesthetic perception and understanding of the good feeling which is transferred by the vision to the brain; the eyes capture the pictures and perceptions are made by light in the nervous system. Meanwhile, the role of light, which is the basis of creation and miracle of existence, is so significant. In the thoughts and minds of man, bright and sunny days are always accompanied with love and happiness and a kind of hopeful encouragement and excitement [1].

\subsection{Light and its symbolic meanings}

In most cultures, light is a symbol for excellence, soaring, perfection, growth, self-confidence and other perfect characteristics. As we have seen in different works of famous painters of different periods of art history, the halo around the saint's head is a sign of reaching towards excellence and perfection of thought and specific ideas of great men. Generally, in most of the world's literary works (poetry and stories), failures and frustrations are likened to the dark night, and all hopes and promises have been likened to the morning dawn [3].

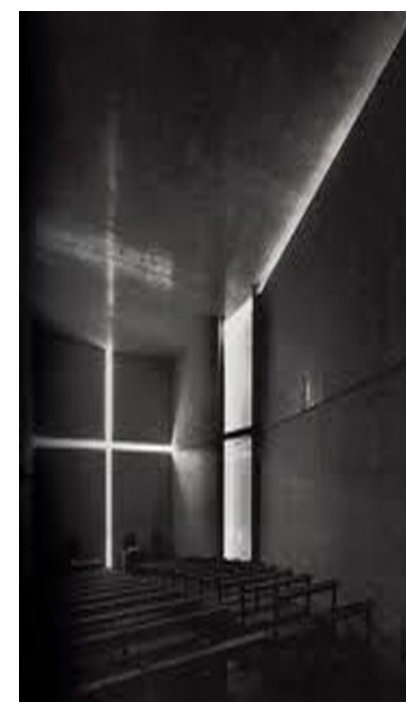

Figure 2: Example of light effect on the quality of space perception.

\subsection{Light and its indirect effects}

Writers and film makers take most advantage of man's perceptions, feelings, natural interpretations and potential reactions to affect their audience by these factors and lateral elements which sometimes have the most important role in transferring messages. They can then guide their audience towards the mood of stories or movies. For example, when they use cloudy, shadow and bright day effects without sufficient light, darkness and thunder in their scenes or outer 
spaces, in fact, they create conditions for showing a crime, robbery or other unethical actions [4].

Light and lighting are the most important factors which cause people to have feelings of happiness by locating in such spaces and places and taking the most pleasure from staying in that environment or, vice versa, they have gloomy, depressed and restless feelings by placing themselves in gloomy spaces and places [5].

\subsection{Effect of light on space perception}

Objective and subjective images from the around world are created in our minds by light and perceptual space is only imaged by understanding the qualities of real space. But it must be noted that our perceptive space is not the same as real space and the subjective image of space is the final outcome that occurs due to perception [6].

Space quality has a special emotional impact on humans and this quality results from its potential characteristics from being active in the presence of light.

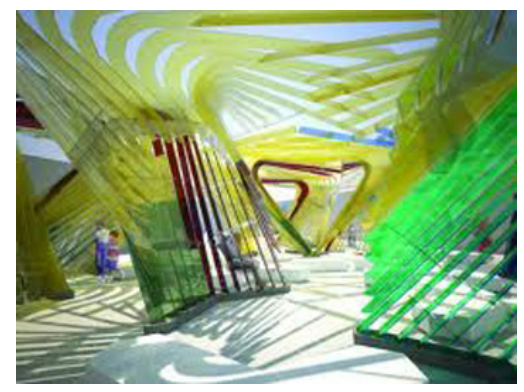

Figure 3: Example of light effect on space perception.

Daylight is a mix of sunlight and skylight. Sunlight is the dominant and main light in nature. It has a warm colour and creates some bright and shadowy regions. Skylight is the secondary light. Its colour is cold and falls on subjects as a soft light. Without skylight, the shadows get dark and the details become invisible [1].

Light affects the quality characteristics of elements and also their specifications depend on light. But space, which is full of uniform light, is completely neutral. Certainly, there is no space in absolute darkness. Unlike these two, the space which is full of light and shade is rich with visual forces and is sensitive, physically and visually [2].

Light affects the physical properties of space and also its body structure and creates the perception of space. The quality of light changes over time. In fact, the fourth dimension of light depends on the perception of space [6].

Aggregation, texture and colour are the potential specifications of space and each of them are solely perceived in the presence of light and the quality and quantity of light makes them stronger or finer. In using natural light, different 
effects of light can be created in space by some changes in colour, texture and aggregation specifications and also by playing with them and making some variations to these specifications [2].

\section{Colour}

Colour is the outcome of physical light reflecting on the surface of objects which are received by the eye and create so many different sensory effects in man. Colour is one of the most important effective qualities in every design. When we look at an object, its colour, dimension and form appear at first glance and then we recognize its texture [7].

Also, colour is more resident in the memory; the form and texture of any object that quickly passes us by may be forgotten but usually its colour remains in the memory. The quality perception of colour levels with natural light sources depends on time and condition and location. In different times, a person may have different perceptions from the same view [7].

Colour is one of the properties of light. Light perception is the result of radiated light, its changes and absorption, reflexive and transitional characteristics of surface, the relation of surface with its surrounding colours and characteristics. Colour is so important in emotions, stimulating the viewer so that his mental reactions are affected. Colour has a unique ability in agitation, to either disturb or relax the viewer. Colour can transfer the feeling of fear, worry and thoughtlessness to the viewer. Controlling colour for stimulating the proper feelings and behaviour from the viewer's point of view is so important for the creating of space. Its spaces and components have essential concepts. The transfer rate of these concepts to the viewer depends on the awareness of the viewer of space and its components. Colour is so important in the presence or absence of these components and concepts [3].

\subsection{Colour properties}

In the manifestation of each colour changing to another colour, each colour will display its essential darkness or brightness in regards to another colour. Reversing this natural order will cause colour incompatibility. Every colour has three changeable characteristics: hue, luminance and saturation [7].

Hue is the quality of colours that determines its place in a series of colours (from red to violet) equivalent to the light of different wavelengths in the visible spectrum. Red, yellow and blue are primary colours and as they form the basis of other hues they are also called major colours. Secondary hues include orange, green and purple which are obtained from mixing equal amounts of two primary hues. Tertiary hues are those which are obtained from the mixing of primary and secondary hues [7].

Luminance is the second quality of colour and determines the relative degree of its brightness and darkness. In the colour cycle, yellow is the most luminous colour (light gray to nearly white) and purple is the least luminous colour (dark gray to nearly black) [7]. 

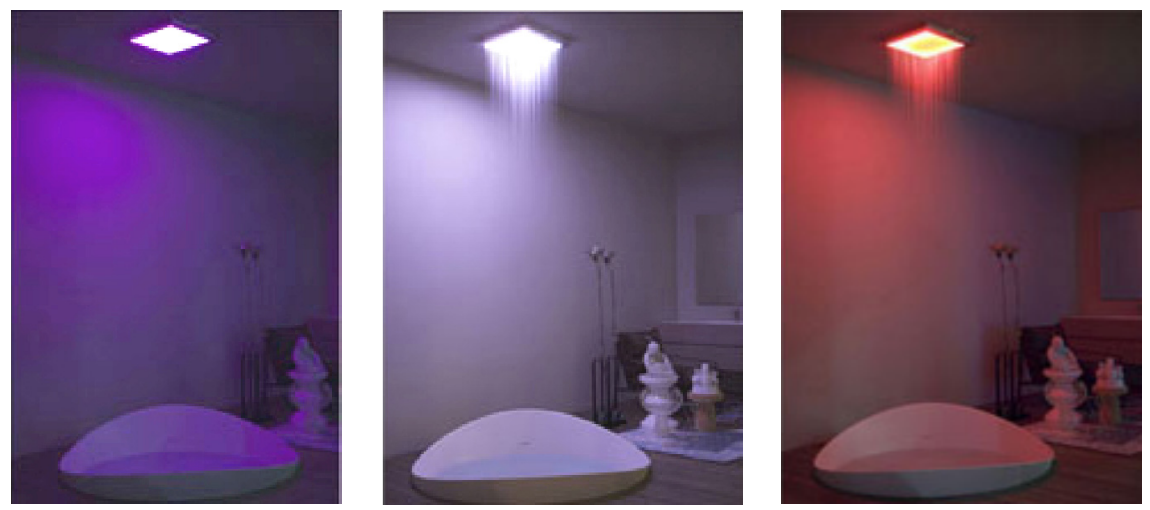

Figure 4: Example of colour effects on the quality of space perception. (See online for colour version.)
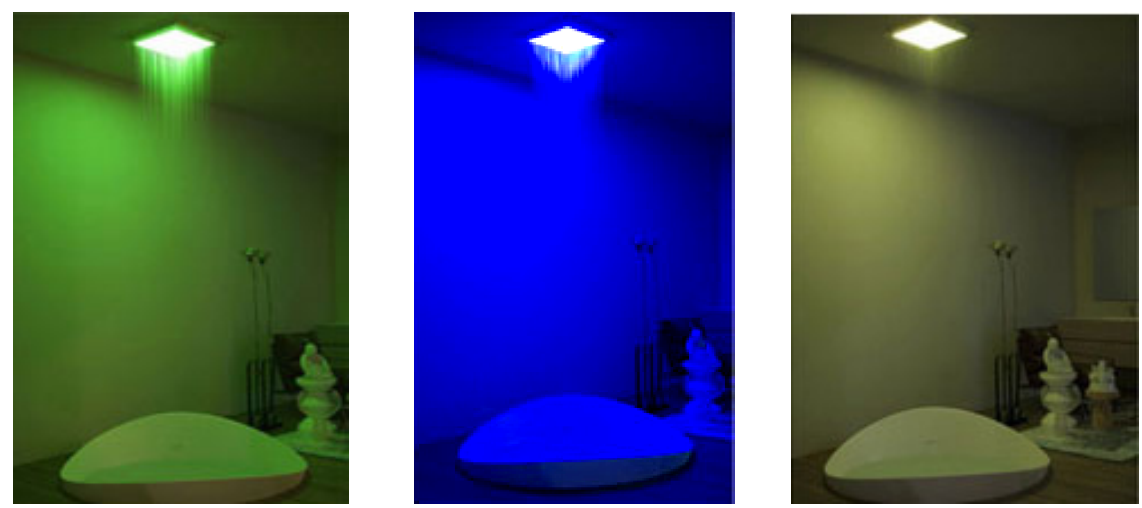

Figure 5: Example of colour effects on the quality of space perception. (See online for colour version.)

Saturation is the third quality of colour and determines its purity level. The purity of the hues of the colour cycle is one hundred percent but in nature we can rarely find a pure hue.

Bright walls and bright backgrounds of cold colours decrease the viewer's body temperature briefly and warm colours momentarily increase the body temperature. Visually, warm colours stick out and cold colours bring back.

Generally, colours are shining forces and energies, which consciously and unconsciously have positive and negative effects on us [6].

\section{Conclusions}

Humans are always surrounded in a real space where their senses determine the boundary of this space. Space without limits is not perceptible to humans. In the infinite space on the horizon, the existence of a shade defines it and gives a 
dimension to it. Space is a frame that only comes into existence after shining light on it. So light is a mediator for the perception of space and space is a place for the objectification of light.

By the presence of light in space, brightness is the thing which we can perceive visually. This brightness has quality and quantity. Brightness is the greatest silent force that our senses can perceive. Light quality is the thing that separates different spaces semantically. Light quality is effective on mental pictures and imagination which are formed in the mind through human perception.

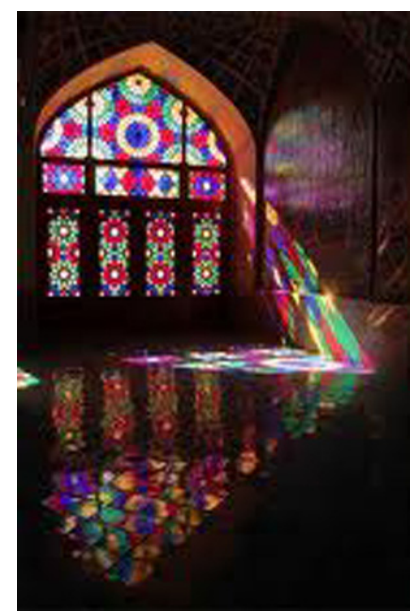

Figure 6: Example of light and colour effects on the quality of space perception.

Space is a phenomenon which is formed as a result of our perception. Perception is the process of data acquisition from the surrounding environment. A subjective and mental process is one that is responsible for selecting and organizing the sensory information and finally adopting the sensory information actively. Perception is a point in which recognition and reality meet each other. Transmitted information from the environment reaches humans through channels. The light channel is a communication channel between humans and space and the information of space is transmitted to humans by this channel. We can conclude that visual perception is created by the tonality of image and background. We live in a world of light. We identify every existence in the world as the images of darkness and brightness at odds with each other. The landscape of space is the only part of space that is perceived by humans.

\section{References}

[1] Ghavami, P., Beauty of light, Soroush: Iran, pp. 15-110, 1997.

[2] Madadpour, M., Spiritual Wisdom and Realms of Art, studies office of Art: Iran, pp. 251-252, 1998. 
[3] Pakzad, J., Aesthetic in architecture, Shahid Beheshti University: Iran, pp. 420-421, 1996.

[4] Halimi, M.H., Fundamentals of Visual Arts, Ehya e Ketab: Iran, pp. 148149, 2005.

[5] Heydari, Sh., Architecture and Lighting, Tehran University: Iran, pp. 77154, 2009.

[6] Jolfayi, A., Philosophical foundations and psychological perception of space, Khak: Iran, pp. 63-67, 2006.

[7] Shirazi, A., Modern Colour, Honar Memari e Gharn: Iran, pp. 84-91, 2008. 